\title{
LOS DELEGADOS DEL GOBIERNO EN ESPAÑA (1997- 2018). PERFILES Y ACTUACIÓN DE UNA FIGURA DE CONFIANZA POLIITICA
}

\section{Government Delegates in Spain (1997-2018). Profiles and activities of a group of trusted political appointees}

\author{
JULIO PONCE ALBERCA \\ Universidad de Sevilla \\ iponce@us.es
}

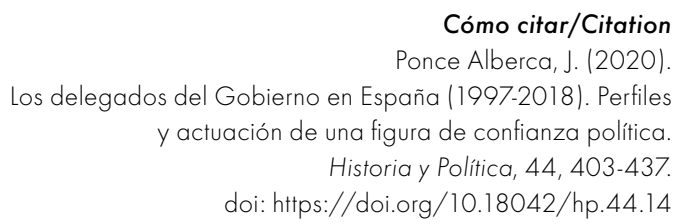

(Recepción: 21/07/2019; evaluación: 31/12/2019; aceptación: 11/03/2020; publicación: 27/11/2020)

\section{Resumen}

Este artículo se centra en el estudio de los delegados del Gobierno desde la supresión de los gobernadores civiles hasta la actualidad. Siendo un objeto de estudio poco tratado hasta la fecha, el papel de los delegados del Gobierno es relevante para entender las relaciones centro-periferia en el marco de la España de las autonomías y su evolución. Para ello hemos construido una base de datos (que aparece recogida en el anexo) y analizado sus biografías a través de fuentes disponibles en la red y la bibliografía disponible. Los objetivos de este trabajo son tres. En primer lugar, se estudia el origen y aparición progresiva de los delegados desde 1980 hasta su definitiva generalización en 1997, año de publicación de la Ley de Organización y Funcionamiento de la Administración General del Estado (LOFAGE). En segundo término, 
se aborda un estudio de los perfiles socioprofesionales y la evolución de las carreras políticas de este personal político desde 1997 hasta 2018. Por último, se analizan algunas de las tendencias que muestra la actuación de los delegados ante las CC. AA. La principal conclusión alcanzada es que los delegados del Gobierno tienen una función representativa y, pese a su labor coordinadora entre el centro y la periferia, no son el principal protagonista de las fricciones entre ambas esferas.

\title{
Palabras clave
}

Estado; Administración; regiones; democracia; España.

\begin{abstract}
This article focuses on the study of government delegates from the elimination of civil governors to 2018. Despite the dearth of studies on the topic, the role of these delegates is relevant to understanding the relationships between centre and periphery in democratic, decentralised Spain. To explore it, we have examined the information provided by the Spanish government gazette (Boletin Oficial del Estado) and the available bibliography. This paper has three key goals. Firstly, it studies the establishment and development of delegates between 1980 and 1997. Secondly, it tackles the study of their social and professional profiles from 1997 to 2018, as well as their political careers. Finally, we pay attention to the relationship between delegates and regional governments. Our most significant conclusion is that delegates have not been key players in possible conflicts between centre and periphery, despite their role in coordinating the relationship between the central government and Spain's autonomous regions.
\end{abstract}

\section{Keywords}

State; Administration; Regions; Democracy; Spain. 
I. MARCO INTRODUCTORIO: LOS DELEGADOS DEL GOBIERNO Y EL ESTADO DE LAS AUTONOMÍAS: 1. La lenta extinción de los gobernadores civiles. 2. La aparición de los delegados del Gobierno: un estado de la cuestión. II. LOS DELEGADOS DEL GOBIERNO (1997-2018): PERFILES SOCIOPROFESIONALES Y CARRERAS POLÍTICAS. III. DELEGADOS Y AUTONOMÍAS: ¿UNA RELACIÓN CONFLICTIVA? IV. CONCLUSIONES. Anexo. Bibliografía.

\section{MARCO INTRODUCTORIO: LOS DELEGADOS DEL GOBIERNO Y EL ESTADO DE LAS AUTONOMÍAS}

\section{LA LENTA EXTINCIÓN DE LOS GOBERNADORES CIVILES}

El comienzo ininterrumpido de la figura de los gobernadores civiles tuvo lugar en $1849^{1}$. Se iniciaba así la configuración centralizada de las provincias que perduraría casi siglo y medio, inspirada en el modelo departamental francés, caracterizado por la presencia de los prefectos como máximos representantes del Estado en el territorio. En España se materializó la jerarquía gobernador-Diputación-Ayuntamiento, donde el primero se convirtió en el representante clave del Gobierno central, consolidando una morfología que permanecería invariable durante la mayor parte del siglo xx con escasas excepciones: la Cataluña autónoma durante la Segunda República (cuando los gobernadores son sustituidos por un gobernador general), las plazas de soberanía (Ceuta y Melilla) que contaban con delegaciones del Gobierno, y la proliferación de autonomías a partir de la década de los ochenta.

1 Real Decreto de 28 de diciembre, de la Presidencia del Consejo de Ministros, creando en sustitución de los Jefes Políticos e Intendentes una sola autoridad civil superior: los Gobernadores Civiles de provincia. Es ya abundante la bibliografía sobre la historia de los gobiernos civiles durante los siglos XIX y xx. Baste indicar aquí tres títulos que sirven para enmarcar este tema. Uno reciente como es el resumen jurídico de Martín Conty y Martín Conty (2017). Otro es el artículo de Alba (2000). Con motivo de la desaparición definitiva de los gobernadores civiles, véase: Ministerio del Interior (1997). 
La transición democrática española no solo significó un profundo cambio de régimen político, sino que también establecería una nueva organización territorial en virtud del título VIII de la Constitución de 1978. El cambio fue muy relevante dentro de una tradición histórica centralizadora, puesto que implicó la puesta en marcha del denominado Estado de las autonomías: una amplia descentralización que iba incluso más allá del Estado integral contemplado por la Constitución de 1931. Y aquella transformación tuvo implicaciones para la organización político-administrativa de las provincias. Por un lado, las diputaciones pasaron a ser entidades contingentes, pues las provincias podrían ser gobernadas por diputaciones «u otras Corporaciones de carácter representativo» (art. 141.2). Por otro, no recogía la más mínima alusión a la figura de los gobernadores civiles, pero en cambio sí indicaba en su art. 154 que un delegado designado por el Gobierno dirigiría la Administración del Estado en la comunidad autónoma. Es decir, los gobernadores deberían haber desaparecido en la medida en que fueron surgiendo autonomías. Sin embargo, no fue así: gobernadores y delegados coexistieron durante algunos lustros antes de la supresión definitiva de los primeros. Incluso, algunos delegados llegaron años más tarde de la creación de la comunidad autónoma (caso de Castilla y León ${ }^{2}$ ), mientras el gobernador de la principal capital se hacía cargo eventualmente de las relaciones con el Gobierno central. ¿Por qué ocurrió esto?

Veamos el proceso. En aplicación del título VIII se convirtieron en comunidades autónomas el País Vasco y Cataluña, y sus primeras elecciones se celebraron en marzo de 1980 . Unos meses más tarde fueron designados los primeros delegados en esos territorios bajo la denominación de «gobernador general», de acuerdo con el Real Decreto 2238/1980, de 10 de octubre (BOE, 254, 22-10-1980). Los dos primeros gobernadores generales fueron Marcelino Oreja Aguirre (gobernador general en el País Vasco) y Josep Meliá Pericás (Cataluña) ${ }^{3}$. Resultaba llamativo que no se les denominase entonces delegados del Gobierno, por cuanto con ese nombre estaban recogidos en el texto constitucional y en la propia disposición citada. Sin embargo, se optó por llamarles "gobernadores generales», no sin alguna polémica entre el Gobierno y algunas formaciones políticas nacionalistas. El Partido Socialista Unificado de Cataluña (PSUC) presentó una moción en el Parlamento catalán contra aquel

2 El primer delegado fue nombrado en septiembre de 1986, cuando su Estatuto se aprobó en febrero de 1983. Aquel primer delegado, Domingo Ferreira, fue nombrado a la vez gobernador civil de Valladolid.

3 Reales Decretos 2042/1980, de 10 de octubre y 2213/1980, de 17 de octubre respectivamente. 
decreto porque «constituye una interpretación centralista y abusiva de la Constitución». Rodolfo Martín Villa, por entonces ministro de Administración Territorial, que lo había sido del Interior, defendió la legalidad de los gobernadores generales, que eran superiores jerárquicos de los gobernadores civiles de las provincias integrantes de la comunidad autónoma ${ }^{4}$. De hecho, no fue casual el que cambiasen todos los gobernadores de las provincias vascas y la mitad de las catalanas pocas semanas después de la llegada de aquellos gobernadores generales 5 .

Aquel fue un primer paso para ir transformando el papel de los gobernadores civiles. Ya no tendrían una interlocución directa con el Gobierno central; se les había interpuesto un gobernador general como un nuevo superior jerárquico que además ejercía la intermediación entre Madrid y las autoridades de la comunidad autónoma. Un segundo paso dio el Real Decreto 3117/1980, de 22 de diciembre, regulador del Estatuto de los Gobernadores Civiles (BOE, 52, 2-3-1981). Aquel decreto - de tardía publicación en medio de las circunstancias del cambio de Gobierno tras la dimisión de Adolfo Suárez- supuso la derogación del antiguo decreto de gobernadores de octubre de 1958 y su acoplamiento al nuevo marco (arts. 12 y 17). No estando reconocidos expresamente en el texto constitucional, los gobernadores civiles fueron reduciéndose a ser un cargo simbólico y representativo del Gobierno en la provincia.

El cambio de Gobierno tras la victoria socialista de 1982 intensificó el desarrollo del Estado de las autonomías y el nombramiento de delegados, pero manteniendo la vigencia de los gobernadores ${ }^{6}$. Estos ya no eran tanto los máximos responsables del orden público en las provincias como los garantes de los derechos y las libertades en coordinación con los poderes autonómicos. Ese cambio cualitativo se reforzaría mediante un real decreto y dos leyes a lo largo de 1983: Real Decreto 1223/1983, de 4 de mayo, sobre Medidas de

4 ElPaís, 2-11-1980, https://elpais.com/diario/1980/11/02/espana/341967604_850215. html.

5 Todos aquellos nombramientos aparecieron en el BOE el 10 de noviembre. Para consultas, ver la base de datos de gobernadores civiles en Espańa (1939-1997): https:// bit.ly/32FvNOg._No obstante, muy pronto la denominación "gobernador general» dejó paso a la de "delegado general del Gobierno" por los Reales Decretos 3184 y 3185, de 22 de diciembre de 1980.

6 En la toma de posesión de cinco delegados (País Vasco, Cataluña, Andalucía, Cantabria y Navarra), el vicepresidente Alfonso Guerra manifestó que «buscamos la cooperación y no la crispación con las comunidades autónomas». Aquellos cinco delegados fueron: Ramón Jáuregui, Francisco Martí, Leocadio Marín, Alicia Izaguirre y Luis Roldán. El País, 31-12-1982. 
Reorganización de la Administración Periférica del Estado (BOE, 117, 17-51983); Ley 10/1983, de 16 de agosto, de Organización de la Administración Central del Estado (BOE, 197, 18-8-1983), y muy especialmente la Ley 17/1983, de 16 de noviembre, sobre Desarrollo del Artículo 154 de la Constitución (BOE, n. 283, 26 noviembre 1983), que vino a consolidar la supremacía de la figura del delegado del Gobierno sobre los gobernadores.

La jerarquía fue compatible con la cohabitación entre delegados y gobernadores durante casi dos décadas (1980-1997) debido a la resistencia de los Gobiernos socialistas a prescindir de los segundos mientras se consolidaba el Estado de las autonomías y se transferían competencias. Valga un simple dato: de los 86 delegados nombrados entre 1980 y 1996 más de la mitad (en torno a un $54 \%$ ) fueron simultáneamente gobernadores civiles de la provincia más importante de la comunidad autónoma. Los gobernadores, pues, subsistieron mientras los Gobiernos autonómicos de Cataluña y el País Vasco siempre presionaron para hacerlos desaparecer ${ }^{7}$. Al no requerir de apoyos parlamentarios entre 1982 y 1993, los Ejecutivos encabezados por Felipe González mantuvieron y reforzaron a los gobernadores en un contexto en el que, además, se hallaba presente la amenaza terrorista. Y ni siquiera cedieron en la última legislatura (1993-1996), cuando el Gobierno del Partido Socialista Obrero Español (PSOE) dependía de los apoyos de los nacionalistas catalanes, liderados entonces por Jordi Pujol. El ministro de la Presidencia, Alfredo Pérez Rubalcaba, dejó bien claro ante los medios que la supresión de los gobernadores no se iba a producir tampoco en aquella legislatura, que sería la última del PSOE${ }^{8}$. No fue hasta 1997, bajo el primer Gobierno del Partido Popular (PP), apoyado por nacionalistas vascos y catalanes, cuando se acometió la supresión de los gobernadores y su definitiva sustitución por delegados y subdelegados del Gobierno?.

\footnotetext{
Las diferencias de criterio con respecto al mantenimiento de los gobernadores fueron especialmente intensas en el seno del PSOE. Si para un gobernador como Goñi Tirapu era preciso mantenerlos $(A B C, 4-2-1990$, p. 27), en línea con el resto del partido $(A B C, 21-2-1990$, p. 27), para los socialistas catalanes era necesaria su supresión $(A B C, 15-10-1990$, p. 23). Por su parte, el Parlamento Vasco se mostró a favor de la supresión de los gobernadores $(A B C, 14-10-1988)$, mientras que los nacionalistas habían denunciado la duplicación de cargos por la existencia de delegados y gobernadores (ABC, 29-10-1987, p. 37).

8 El Pais, 11-12-1993, https://elpais.com/diario/1993/12/11/espana/755564424_850215. html.

9 El Pais, 1-5-1997, https://elpais.com/diario/1997/05/01/espana/862437620_850215. html.
} 
Como hemos indicado, hubo delegados que nunca fueron gobernadores civiles con anterioridad (menos de la mitad de los nombrados entre 1980 y 1996), como fueron los casos de Marcelino Oreja (País Vasco), Josep Meliá (Cataluña), Ramón Jáuregui (País Vasco) o Domingo García-Sabell Rivas (Galicia). Y hubo gobernadores que fueron delegados - la mayoría-, como Francisco Javier Ansuátegui Gárate (gobernador en Navarra y delegado del Gobierno ante la Comunidad Foral), Alicia Izaguirre (gobernadora en Santander y delegada en Cantabria), Juan Ramírez Piqueras (gobernador en Badajoz y delegado en Extremadura) o Amparo Rubiales (gobernadora en Sevilla y delegada para Andalucía). Gracias al testimonio de esta última hemos podido comprobar cómo se compatibilizaba la doble condición de gobernadora civil en una provincia y delegada del Gobierno ante una comunidad autónoma, dándole preferencia al segundo cargo y cediendo el funcionamiento del Gobierno Civil en favor del secretario general. Y es que la cotización del gobernador civil había caído muchos enteros para los años noventa. No es extraño que la propia Amparo Rubiales rechazase el cargo de gobernadora civil de Sevilla, ofrecido por el ministro del Interior José Luis Corcuera: «La próxima vez que me pidas algo que sea por lo menos para ser delegada del Gobierno». Accediendo a sus deseos, el ministro le ofreció en septiembre de 1993 los dos cargos simultáneamente ${ }^{10}$.

La cohabitación de gobernadores y delegados se fue generalizando en detrimento de los primeros, que pasaron a ser una especie de gobernadores de segundo orden. Ya el art. 6. del mencionado Real Decreto 2238/1980, de 10 de octubre, concedía al gobernador general «[...] su superior autoridad sobre los gobernadores civiles de las provincias comprendidas en la Comunidad Autónoma y, a través de ellos, sobre todos los órganos de la administración periférica civil del Estado». Los delegados no contaron expresamente entre sus facultades con el nombramiento de gobernadores civiles, pero sí parece ser que tenían influencia ante el Ministerio del Interior. Por ejemplo, la delegada Amparo Rubiales promovió el nombramiento de gobernadoras civiles para algunas de las provincias andaluzas ante el ministro Juan Alberto Belloch ${ }^{11}$.

La situación de facto era por tanto de práctica subordinación de los gobiernos civiles a las delegaciones de Gobierno. Tan solo faltaba que se produjera un cambio de Gobierno para vencer la última resistencia que los gabinetes socialistas siempre mostraron con respecto a la supresión definitiva de los gobernadores. Eso ocurrió en 1996 cuando se constituyó el primer Gobierno del PP, encabezado por José María Aznar. Al requerir entonces del

10 Rubiales Torrejón (2008): 298.

11 Ibid.: 309. 
apoyo de los partidos nacionalistas, estos exigieron la desaparición de los gobiernos civiles y Aznar respondió meses más tarde con la Ley 6/1997, de 14 de abril, de Organización y Funcionamiento de la Administración del Estado (LOFAGE), publicada en el BOE el 15-4-1997'2. A partir de entonces solo existirían delegados y subdelegados del Gobierno.

\section{LA APARICIÓN DE LOS DELEGADOS DEL GOBIERNO: UN ESTADO DE LA CUESTIÓN}

El art. 154 de la Constitución de 1978 afirmaba textualmente: «Un delegado nombrado por el Gobierno dirigirá la Administración del Estado en el territorio de la Comunidad Autónoma y la coordinará, cuando proceda, con la administración propia de la Comunidad». Teniendo en cuenta la implantación progresiva de las delegaciones del Gobierno, podemos distinguir tres períodos a la hora de analizar los estudios disponibles y monográficos sobre este tema. Entre 1979 y 1985 se publicaron una serie de artículos que exploraban tanto la configuración jurídica de aquella figura como su establecimiento en la medida en que se desarrollaba el Estado autonómico. Un segundo grupo de trabajos vieron la luz entre 1986 y 1997, desde la generalización de las autonomías hasta la definitiva desaparición de los gobernadores civiles. Por último, tenemos el conjunto de estudios realizados a partir de la aparición de la LOFAGE. Aunque este trabajo se centra en el análisis de los delegados desde 1997 (y hasta junio de 2018), consideramos de interés abordar la panorámica general del estado de la cuestión sobre el tema.

Analicemos someramente el primer grupo. Según la bibliografía consultada, una aportación pionera fue el artículo de Enrique Linde Paniagua titulado «El delegado del Gobierno», en el que adoptaba un ángulo de análisis basado en los antecedentes históricos de este cargo sin olvidar una perspectiva comparada (el comisario del Gobierno creado por la Constitución italiana de 1947). Una parte interesante de aquel trabajo es su pormenorizada descripción de las discusiones de la ponencia constitucional —en el Congreso y en el Senado-, que desembocarían en la redacción final del art. 154. Del mismo

12 El acuerdo fue negociado por Rodrigo Rato (PP) y Joaquim Molins (Convergència). En virtud del mismo se acordaron entre otros extremos: cesiones del IRPF a favor de las autonomías, supresión futura del servicio militar obligatorio, transferencia de los puertos, del Instituto Social de la Marina, rebaja del IVA en los peajes de las autopistas y desaparición de los gobernadores a favor de delegados y subdelegados (estos últimos como funcionarios sin rango político). Véase: El Pais, 27-4-1996. 
modo, allí se planteaba cuál será el papel concreto de estos delegados ante los trece regímenes preautonómicos de aquel entonces y cuál sería su papel coordinador con la Administración autonómica emergente. En el fondo, aquel perspicaz trabajo jurídico de Linde apuntaba ya tres problemas no resueltos que tendrían proyección en los lustros posteriores: a) la relación delegados-gobernadores civiles; b) la imprecisión jurídica de la figura del delegado a la hora de aclarar si era esencialmente representativa o ejecutiva, y c) su papel coordinador "cuando proceda» ante la comunidad autónoma. Con variaciones sobre la misma melodía estos mismos aspectos también serían tratados por Calvo González, Díaz de Liaño-Vallés Copeiro y Cámara del Portillo ${ }^{13}$. El panorama no había cambiado sustancialmente en 1983, cuando el abogado del Estado Ureta Domingo publicó otro trabajo en el que, también basándose en comparaciones con otros países de nuestro entorno, concluía que faltaba definición en el papel de las delegaciones del Gobierno como consecuencia del heterogéneo proceso de construcción del Estado autonómico, con techos competenciales diferentes en cada comunidad ${ }^{14}$.

El segundo período (1985-1997) estuvo dominado por estudios centrados en aspectos técnicos y monografías que trataban de enmarcar la figura de los delegados dentro de un contexto de clara decadencia de los gobiernos civiles. Todos ellos seguían un marcado carácter jurídico, en ausencia de análisis realizados desde otras áreas de conocimiento. Muestras de estudios técnicos fueron el trabajo de Luis de la Morena sobre competencias de delegados y gobernadores en materia de personal, diversos informes del Instituto Nacional de Administración Pública (INAP) o las aportaciones de Martín Bassols y Ángel Luis Alonso ${ }^{15}$. Mayor interés encerraron las monografías que comenzaron a aparecer desde finales de los años ochenta, en unas fechas en las que se iba generalizando aquella figura. Nos referimos a los libros de Rafael Salaberri, Aquilino González y a la tesis doctoral de José María Quiroga de Abarca ${ }^{16}$. Son estudios muy completos en los que se sitúa la figura del delegado apuntando dos detalles importantes: su coexistencia con los gobernadores y su relativa indefinición ante las comunidades autónomas, así como su carácter representativo (del Gobierno central), pero lejos de una capacidad ejecutiva dotada de competencias que fuesen más allá de la seguridad ciudadana.

13 Linde Paniagua (1979); Calvo González (1979-1980); Díaz de Liaño y Vallés (1980), y Cámara del Portillo (1981).

14 Ureta Domingo (1983).

15 Morena y de la Morena (1985); Instituto Nacional de Administración Pública (1990); Bassols Coma (1988), y Alonso de Antonio (1997).

16 Salaberri Barañano (1989); González Hernando (1990), y Quiroga de Abarca (1994). 
Con la publicación de la LOFAGE (1997) se despejó definitivamente la mezcolanza gobernadores-delegados. Precisamente fue entonces cuando aparecieron algunas obras generales sobre la historia de los gobernadores civiles, también bajo una óptica jurídica o basada en testimonios personales. Para lo que nos atañe, tan solo citaremos el libro recopilatorio publicado por el Ministerio del Interior o un interesante artículo sobre el origen, desarrollo y desaparición de los gobernadores en perspectiva comparada ${ }^{17}$. Se cerraba una etapa y se abría otra con delegados y subdelegados del Gobierno, ya dentro de un modelo cerrado de Estado autonómico tras la conversión de Ceuta y Melilla en ciudades autónomas (1995). El enfoque de los estudios seguía siendo jurídico (encaje de los delegados con los servicios territoriales de los diversos ministerios del Gobierno central, reforma de la Administración del Estado, reforma del Estado de las autonomías, etc. $)^{18}$, aunque se incorporaron otras perspectivas que se planteaban incluso la pertinencia de las delegaciones y subdelegaciones del Gobierno en un Estado de vocación claramente descentralizadora ${ }^{19}$. Una conclusión que se desprendía de estos trabajos era la falta de concreción de las funciones de las delegaciones del Gobierno más allá de las de seguridad. En otras palabras, al disponer las comunidades autónomas de amplias competencias, el delegado del Gobierno carecía de misiones precisas, quedando reducido a servir de coordinador y armonizador de las relaciones entre el Gobierno central y los Gobiernos autonómicos. Es más, en el propio diseño constitucional (arts. 148 y 149) se dejaba la vía abierta a una cesión progresiva de competencias en favor de las autonomías, lo que invitaba a no fijar nítidamente las funciones de los delegados del Gobierno para su encaje dentro de las variables relaciones entre centro y periferia. Naturalmente, este tercer grupo bibliográfico - publicaciones desde 1997- es el que más nos interesa para los cometidos del presente trabajo ${ }^{20}$.

Tras el estado de la cuestión expuesto salta a la vista que no disponemos de un estudio de los delegados - y delegadas - del Gobierno en cuanto personal político, en contraste con otros conjuntos como, por

Ministerio del Interior (1997) y Alba (2000).

18 Oliván del Cacho (1998); Zafra Jiménez (1998); Expósito Gómez (2005); González Escudero (2004); Bueno Sánchez (2015), y Sarmiento Larrauri (2016).

19 González Aperribay (2011): 11-13.

20 A este tipo de estudios habría que añadir análisis sobre las relaciones entre el Estado y las comunicades autónomas, como los siguientes: Agranoff y Ramos Gallarín (1997); Aja y Colino (2014); Aja (2014); Albertí Rovira (1985); García et al. (2006), y López Nieto (2006). 
ejemplo, el de los parlamentarios ${ }^{21}$. Es decir, carecemos de un análisis que trascienda el marco jurídico y que profundice en las biografías públicas de estos delegados (sobre todo sus perfiles socioprofesionales y políticos) y en sus relaciones concretas con las Administraciones autonómicas. Este es precisamente el objetivo de estas páginas, en las que se analiza el conjunto de delegados nombrados en la antesala de la aparición de la LOFAGE hasta la última ronda de nombramientos tras la configuración del primer Gobierno de Pedro Sánchez Castejón (junio de 2018). Quedan fuera de este estudio las subdelegaciones de Gobierno. Del mismo modo — por las mismas razones de limitación - vamos a acotar el estudio de la actuación de los delegados del Gobierno ante las comunidades autónomas a la verificación del nivel de conflicto en función del color político del Gobierno central (del cual es representante el delegado) y de la comunidad autónoma. Es decir, pretendemos saber si el diferente color político del delegado y la autonomía suele venir acompañado de conflicto o no.

\section{LOS DELEGADOS DEL GOBIERNO (1997-2018): PERFILES SOCIOPROFESIONALES Y CARRERAS POLÍTICAS}

Hacia finales del mes de abril de 1996, José María Aznar y Jordi Pujol alcanzaron un acuerdo de gobernabilidad (conocido como el Pacto del Majestic) tras acordar — entre otros extremos — la profesionalización del Ejército, la cesión de las competencias de tráfico, de un mayor porcentaje del IRPF y la desaparición de los gobernadores civiles. Aquel pacto tuvo un efecto inmediato porque el 18 de mayo fueron nombrados diecinueve delegados del Gobierno que ya carecían de la condición de gobernadores civiles. Y eso ocurría casi un año antes de la publicación de la LOFAGE, lo cual induce a pensar que la futura desaparición de los gobiernos civiles se daba ya como cosa hecha. Por su parte, los gobernadores civiles entonces designados pasarían a ser subdelegados.

Lo que ocurrió en 1996 fue un reemplazo completo que volvería a repetirse cada vez que cambiase el matiz político del Gobierno (años 2004, 2011 y 2018). Sin embargo, y en comparación, las designaciones descendían en los años en los que ganaba los comicios el partido que sustentaba al Gobierno (2000, 2008, 2015 o 2016). Así lo demuestra el siguiente gráfico que muestra la distribución anual de nombramientos de delegados:

21 Coller (2016) o Jerez et al. (2012). 
Gráfico 1. Numero de nombramientos de delegados por año

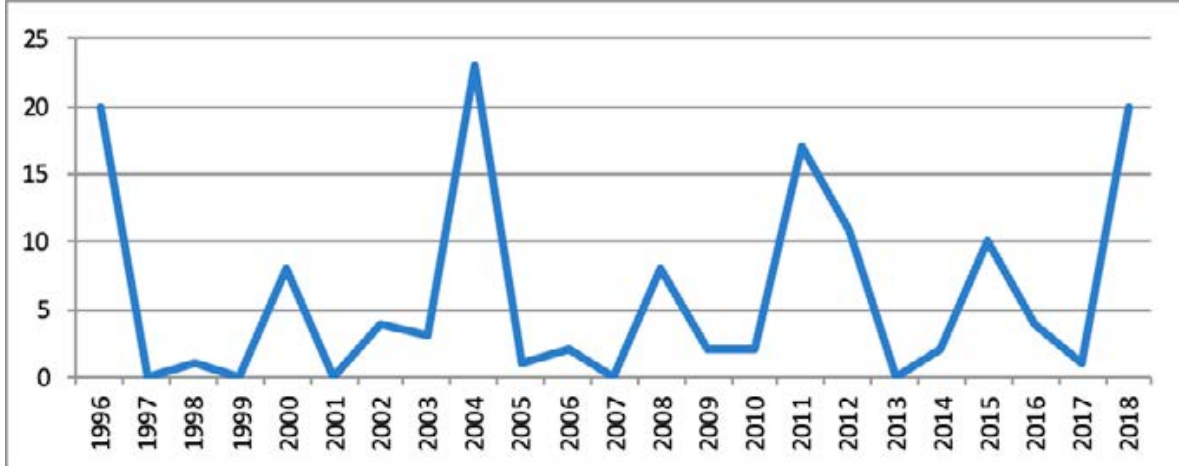

Fuente: base de datos elaborada a partir de los nombramientos de delegados en el BOE.

El gráfico evidencia la estrecha dependencia de los delegados de los avatares del Gobierno central. Incluso cuando este no cambió de manos también se detecta un incremento de nombramientos al objeto de afinar las relaciones con las autonomías y, en su caso, ajustar los posibles huecos dejados por delegados que pasaron a ocupar otro tipo de cargo. Por el contrario, el cambio político en las comunidades autónomas no parece tener importancia relevante a la hora de explicar el ritmo de nombramiento de los delegados del Gobierno. Según nuestros datos, tan solo algunos delegados fueron removidos excepcionalmente tras unas elecciones en la autonomía de destino. Fueron los casos de Jesús Labrador Encina (Castilla-La Mancha, 2012-2015) y Serafín Castellano Gómez (Comunidad Valenciana, 2014$2015)^{22}$.

La frecuencia de los reemplazos en las delegaciones no fue homogénea si observamos las diferentes comunidades autónomas. Entre 1996 y 2018 se han registrado 138 designaciones (sobre 134 delegados, pues cuatro de ellos repitieron cargo $)^{23}$ distribuidas por comunidad del modo siguiente:

22 A las dos comunidades llegó el PSOE en 2015 y eso favoreció la sustitución del primero por José Julián Gregorio López (2015-2018) y del segundo por Juan Carlos Moragues (2015-2018), aunque es obligado precisar que Castellano fue destituido por un caso de corrupción.

23 Fueron los casos de Francisco Javier Ansuátegui Gárate, José Fernández Chacón, Carlos María Urquijo Valdivielso y Juan Ignacio Zoido Álvarez (ver anexo). 
TABla I. Número de delegados del Gobierno por autonomía (1996-2018)

\begin{tabular}{ll}
\hline \multicolumn{1}{c}{ Comunidad autónoma } & Número de nombramientos \\
\hline Andalucía & 8 \\
\hline Aragón & 5 \\
\hline Asturias & 7 \\
\hline Canarias & 9 \\
\hline Cantabria & 5 \\
\hline Castilla y León & 6 \\
\hline Castilla-La Mancha & 9 \\
\hline Cataluńa & 7 \\
\hline Ceuta & 8 \\
\hline Comunidad Valenciana & 11 \\
\hline Extremadura & 6 \\
\hline Galicia & 9 \\
\hline Baleares & 7 \\
\hline La Rioja & 4 \\
\hline Madrid & 9 \\
\hline Melilla & 7 \\
\hline Murcia & 8 \\
\hline Navarra & 6 \\
\hline País Vasco & 7 \\
\hline
\end{tabular}

Fuente: nombramientos de delegados en el BOE. Elaboración propia.

Puede comprobarse una sensible amplitud entre los cuatro delegados nombrados para La Rioja y los once de la Comunidad Valenciana. La razón de los reemplazos frecuentes en comunidades como Galicia, Valencia, Canarias, Castilla-La Mancha o Madrid están relacionados con promociones políticas dentro del partido, conversión del delegado/a en candidato/a electoral, pase a otros cargos de responsabilidad o cese por casos de corrupción. No parece verificarse que el diferente color político del delegado y la comunidad autónoma fuese causa de un mayor número de reemplazos. En La Rioja, por 
ejemplo, hubo diferentes partidos al frente de ambas instituciones y sin embargo se mantuvo una mayor estabilidad que en comunidades como la Valenciana o Madrid, con mayor predominio del PP tanto en la Delegación del Gobierno como en la Presidencia de la comunidad autónoma. Globalmente, el mandato medio de los delegados ha sido de unos tres ańos y medio, lo que viene a indicar que casi cada cuatro ańos se produce el reemplazo del delegado. Un poco menos del tiempo de duración teórica del Gobierno surgido tras unas elecciones.

Conocemos la edad de más del $89 \%$ de los delegados nombrados a partir de 1997. Más de las tres cuartas partes tenían entre 40 y 60 años (un $38 \%$ entre 40 y 49 años y un $40 \%$ entre 50 y 59) al tomar posesión de las delegaciones (una media en torno a 52 años). Sabemos también que la mayor parte (un $71 \%$ ) nacieron en la misma comunidad a la que fueron destinados, algo muy distinto a lo que ocurría con los gobernadores civiles, que tradicionalmente no solían ser - salvo excepciones- originarios de la provincia de destino. Tradicionalmente se buscaba que los gobernadores - desde una concepción centralizada del Estado- no tuviesen lazos ni intereses con los grupos dirigentes locales. Sin embargo, el Estado de las autonomías se fundó sobre la búsqueda de una sintonía centro-comunidades basada en la lealtad y el respeto institucional; de ahí la tendencia a procurar que los delegados del Gobierno conocieran bien la autonomía a la que eran enviados. Y esta característica tuvo consecuencias: la práctica totalidad de los delegados lo fueron solamente una vez en su carrera política. Hoy en día no es habitual la rotación o combinación de delegados, como se hacía en otra época con los gobernadores.

La práctica totalidad de los delegados presenta una formación universitaria, generalmente licenciados frente a un reducido número de doctores y de grados medios. El grupo mayoritario, más del $40 \%$, es el de licenciados en Derecho, seguidos a mucha distancia por economistas (15\%) y licenciados en Ciencias Sociales y Humanidades (11\%). La profesión habitual es la de funcionarios civiles vinculados al mundo del derecho o la docencia, lo cual ratifica la sobrerrepresentación relativa de empleados públicos en las esferas políticas, con sus consecuencias derivadas ${ }^{24}$. Es significativo el bajo número de delegados procedentes de la actividad privada (menos del $7 \%$ de las profesiones conocidas). Se detecta también una asimetría en términos de género: solo un $28 \%$ del total de los 134 delegados analizados fueron mujeres.

24 La presencia de funcionarios en el personal político es elevada entre los diputados (https:// cadenaser.com/ser/2011/12/14/espana/1323823834_850215.html), como también lo es en el conjunto analizado. Las consecuencias de la estrecha relación entre políticos y funcionarios han sido analizadas por Carles Ramió (2016). 
¿Desempeñar el cargo de delegado del Gobierno favorece el desarrollo de una carrera política? La respuesta es afirmativa, pues la mayor parte pasó a ocupar otro cargo (en torno a un $60 \%$ ). Generalmente promocionaron dentro de sus respectivas organizaciones partidistas, convirtiéndose en candidatos electorales. Pero algunos lograron promocionar hacia otro tipo de responsabilidades (director general, consejeros en embajadas fuera del país, etc.). Solo una minoría es destinada a otras delegaciones de Gobierno: concretamente, cuatro de ellos repitieron cargo. Pero no todos prosiguieron su carrera: aproximadamente uno de cada cuatro volverá a su pasada actividad profesional.

Sí es llamativo, en cambio, que casi todos ellos mostrasen una experiencia política previa o, en su defecto, una trayectoria profesional relevante. Entre los 134 delegados se detectan un buen número de cargos anteriores: 41 concejalías, 27 alcaldías, 75 mandatos de diputado y 16 de senador. Cargos que fueron simultáneos (por compatibles) o bien fueron desempeńados en distintos años. Ahora bien, después de haber sido delegados solo encontramos tres concejales, seis alcaldes, veintiún diputados y ocho senadores. Estos datos parecen demostrar que el cargo de delegado ha sido desempeñado desde 1996 en etapas biográficas de relativa madurez profesional y política. La notable experiencia previa (superior a la experiencia política posterior) y la elevada edad media en la toma de posesión (51 años) avalan lo expuesto.

Lógicamente, casi todos han pertenecido a los partidos mayoritarios que han formado Gobierno en Espańa: más de la mitad de los mandatos de delegados estuvieron en manos del PP (54\%), seguido del PSOE (un $43 \%$ ), siendo excepcionales los delegados independientes. Ello responde a su condición de personal de confianza del Gobierno central. Por otra parte, esas adscripciones son únicas; es decir, el delegado solo ha pertenecido a un partido. Aunque hubo excepciones en el caso del PP: dos delegados militaron en su día en organizaciones del Movimiento para pasar luego a la UCD y, posteriormente, al PP (Ameijide Montenegro y Ansuátegui Gárate); otro militó en Unión Tudense para pasar al PP (Diz Guedes, que recientemente ha pasado a Ciudadanos).

Siendo estos los trazos generales del conjunto, pueden destacarse algunos ejemplos ilustrativos. Uno es el de Isaías García Monge, delegado en Castilla y León desde 1996 hasta 2004 bajo los dos gobiernos de José María Aznar y buen conocedor de la región no solo por haber nacido en ella, sino porque allí fue consejero de Agricultura y Ganadería entre 1991-1996. Es decir, García Monge pasó del Gobierno autonómico directamente a la Delegación del Gobierno. Tras cesar en el cargo, con alrededor de 58 años, no proseguiría una carrera política, pero sí fue premiado con la vicepresidencia de Caja 
Duero, continuando así su vinculación con Castilla y León ${ }^{25}$. Este caso encaja en el modelo expuesto de delegados relativamente envejecidos que no mantendrían una trayectoria política posterior de fuste. Recorrido similar efectuó Javier Fernández López, delegado en Aragón durante las dos legislaturas de José Luis Rodríguez Zapatero tras ser profesor de Derecho Constitucional en la Universidad de Zaragoza. Era oriundo de la región de destino, como tantos otros delegados, pero en él se daba la singularidad de ser también coronel del Ejército, lo cual es destacable porque desde 1977 no era frecuente encontrar a militares al frente de gobiernos civiles o delegaciones del Gobierno. Fue un independiente - aunque considerado progresista - que tampoco iba a tener actividad política posterior. Su caso sería similar al de Agustín Ibáńez Ramos (Cantabria) o al de Joan Rangel i Tarrés (Cataluña), todos ellos técnicos o profesionales, de edad relativamente alta y ninguno de ellos disfrutó de continuidad en la política.

La exploración de otros casos añade algunos matices. Un ejemplo fue el de Julia García-Valdecasas Salgado, delegada en Cataluña entre 1996 y 2003. Su biografía también refleja un claro perfil técnico. Nacida en 1944 en Barcelona, fue farmacéutica y luego sacó las oposiciones del Cuerpo de Interventores y Auditores del Estado. Tras ocupar puestos como alta funcionaria saltó a la política como delegada pero - a diferencia de otros compañeros de cargo- prosiguió una trayectoria ascendente hasta llegar a ministra de Administraciones Públicas (2003-2004). Más tarde fue diputada nacional por Barcelona (2004-2006 ${ }^{26}$. Su permanencia al frente de la Delegación tuvo similitudes con algunos de los ejemplos expuestos anteriormente, pero su promoción posterior fue claramente diferente. Alberto Bretón Rodríguez, delegado en La Rioja bajo los gobiernos de Mariano Rajoy (2011-2018), fue letrado en el Gobierno de aquella comunidad como funcionario de carrera y tras la moción de censura de Pedro Sánchez Castejón se refugió en cargos de su partido. Otros delegados, sin embargo, desplegaron una vida política posterior, como fueron los casos de Francisco Camps, Cristina Cifuentes y Juan Ignacio Zoido Álvarez. El primero fue delegado en Valencia durante unos meses en el año 2002, para luego presentarse a las elecciones y convertirse en presidente de la Comunidad Valenciana. Cristina Cifuentes fue delegada en Madrid (2012-2015) antes de ser diputada y presidente en la Comunidad de Madrid hasta su dimisión. En el último ejemplo, sabemos que Zoido fue dos veces delegado: la primera en Castilla-La Mancha (2000-2002), y la

\footnotetext{
25 En este papel de gestor de Caja Duero se vería envuelto en el caso Nozal y la polémica que ha rodeado la politización de las cajas de ahorro. Véase: https://bit.ly/3jDVPHa.

26 Se retiró de la política en 2006 y falleció en 2009.
} 
segunda en su Andalucía natal (2002-2004). Tras ser delegado sería diputado autonómico, alcalde de Sevilla y ministro del Interior.

Cabe concluir este epígrafe señalando que un significativo porcentaje de los delegados fueron diputados o senadores (o ambas cosas) en algún momento de sus carreras políticas, sobre todo antes de ser delegados. Del conjunto de 134 delegados, 45 lo fueron en varias legislaturas. De estos, casi la mitad pasaron por el Congreso de los Diputados y alrededor de un $15 \%$ fue senador, mientras que dieciséis estuvieron tanto en el Congreso como en el Senado. En buena medida, estos datos ratifican que los delegados suelen tener una experiencia política previa notable.

\section{DELEGADOS Y AUTONOMÍAS: ¿UNA RELACIÓN CONFLICTIVA?}

Según el testimonio de Amparo Rubiales (delegada del Gobierno en Andalucía entre 1993 y 1996), son excepcionales los roces de un delegado con otros cargos institucionales del mismo color político: «Cuando fui delegada del Gobierno no tuve ningún problema de coordinación con el Gobierno de la Junta de Andalucía; con su presidente, Manuel Chaves, las relaciones personales y políticas eran inmejorables, y con los consejeros, también; con los que más relación profesional tenía era con los consejeros o consejeras de Gobernación ${ }^{27}$.

Es cierto que tuvo alguna diferencia con el gobernador civil de Cádiz (el también socialista César Braña) por la dura represión de las manifestaciones de astilleros, pero en su día no llegaron a saltar a la prensa. Esas divergencias - discretamente silenciadas - no podían compararse con las que sostuvo con el ayuntamiento que estaba en manos del PP y los andalucistas (Soledad Becerril y Alejandro Rojas-Marcos. respectivamente):

Cuando llegué a la Delegación del Gobierno, los enfrentamientos con el gobierno local de Rojas Marcos-Becerril fueron continuos; con acusaciones tan peregrinas como la de que yo estaba retirando a la Policía Nacional de Sevilla, y esto lo declaran el 14 de septiembre de 1993, cuando no llevaba ni una semana en el cargo. Así siguió siempre, sobre todo mientras Alejandro fue alcalde; con Soledad he de decir que las cosas fueron mucho mejor y la colaboración, más estrecha ${ }^{28}$.

Esa fue la experiencia de una delegada del Gobierno en Andalucía. Es una aportación cualitativa interesante, pero se refiere a unos años en los que

27 Rubiales Torrejón (2008): 303.

28 Ibid. 300. 
ni siquiera se había producido la implantación definitiva de delegados y subdelegados. Y por ello cabe plantearse: ¿es representativo este testimonio de lo que ocurrió en el período 1997-2018? ¿Se producen roces y conflictos habituales entre las delegaciones del Gobierno y las comunidades autónomas cuando están gobernadas por partidos políticos distintos y, al contrario, todo es sintonía cuando ambas se encuentran en manos del mismo partido? Esto es precisamente lo que queremos comprobar en este último epígrafe.

Para iniciar nuestro análisis contabilizamos el color político de los 138 mandatos de delegados de Gobierno. Nótese que no estamos ante los 134 delegados nombrados, sino ante sus mandatos por cuanto - como ya indicamos- algunos delegados repitieron el cargo en varias delegaciones. Aquellos 138 nombramientos —entre mayo de 1996 y junio de 2018 - fueron destinados a comunidades autónomas de diverso matiz político. La siguiente tabla representa las interacciones entre mandatos de delegados designados por las diversas fuerzas (normalmente PP y PSOE) frente a comunidades autónomas de variado color político.

Tabla 2. Número de mandatos en delegaciones del Gobierno por filiación politica del delegado y de la comunidad autónoma (1996-2018)

\begin{tabular}{lcccccccccc}
\hline \multicolumn{10}{c}{ Partido gobernante en comunidad autónoma } \\
\hline $\begin{array}{l}\text { Militancia } \\
\text { política }\end{array}$ & PP & PSOE & $\begin{array}{l}\text { PP/PSOE } \\
\text { PSOE/PP }\end{array}$ & $\begin{array}{l}\text { PNV y otros } \\
\text { nacionalistas }\end{array}$ & $\begin{array}{c}\text { CiU yotros } \\
\text { nacionalistas }\end{array}$ & $\begin{array}{c}\text { Coalición } \\
\text { Canaria }\end{array}$ & UPN & Otros & Total \\
\hline PP & 30 & 16 & 11 & 3 & 3 & 3 & 1 & 8 & 75 \\
\hline PSOE & 27 & 10 & 4 & 3 & 2 & 5 & 2 & 6 & 59 \\
\hline Otros & 0 & 0 & 1 & 0 & 0 & 1 & 0 & 2 & 4 \\
\hline Totales & 57 & 26 & 16 & 6 & 5 & 9 & 3 & 16 & 138 \\
\hline
\end{tabular}

Fuente: nombramientos de delegados en el BOE. Elaboración propia.

Como se observa, la mayor parte de los mandatos de delegados recayeron en el PP (75) y PSOE (59), además de cuatro casos excepcionales (dos independientes y otros dos de los que desconocemos su filiación). También se verifica que hay una mayoría de legislaturas autonómicas del PP (57) sobre otras fuerzas políticas. Hemos de precisar las columnas cuarta y novena: en ellas tenemos mandatos que asistieron a un cambio de Gobierno autonómico (pasó del PP al PSOE o del PSOE al PP) sin que el delegado o delegada cambiase, o bien otras combinaciones en la columna «Otros» (Gobiernos de CiU que 
pasan al PSOE, Partido Regionalista de Cantabria, Foro Asturias, Gobiernos del PSOE que pasan al PNV, etc.). Nuestra hipótesis se recoge también en la tabla: consideramos que en las casillas sombreadas en gris (coincidencia de partido en la Delegación del Gobierno y en la Comunidad Autónoma) se producen menos conflictos que en las demás.

Para detectar la presencia de conflicto vamos a recurrir a las noticias de prensa, lo cual nos obliga a plantear dos precisiones metodológicas: la definición de conflicto y el problema del uso de la prensa. En primer lugar, vamos a definir conflicto como el enfrentamiento público entre la Delegación del Gobierno y el Gobierno autonómico. Por extensión también incluiremos al Parlamento regional como actor porque del mismo sale elegido el Gobierno autonómico, conforme a las bases de nuestro sistema de representación. En segundo, se recurre a la prensa porque cuando el enfrentamiento es evidente y se hace público precisamente lo hace a través de los medios de comunicación. La prensa digital permite búsquedas rápidas a través de internet y eso la convierte en un recurso apreciable. No obstante, esta estrategia de investigación presenta una debilidad cuando el enfrentamiento institucional no trasciende y, por tanto, no es recogida en los medios. Esos casos quedan fuera de nuestro ángulo de observación y, en consecuencia, los ejemplos detectados de conflicto delegado/comunidad que incluimos aquí son una muestra; es decir, no son cifras concluyentes, aunque sí podemos considerarlas muy indicativas del nivel de conflicto. Las búsquedas han sido realizadas en la red a partir de los nombres y apellidos de los delegados.

¿Qué nos dice la prensa sobre el nivel de conflicto entre autonomías y delegados del Gobierno? Lo primero que señala es que el número de controversias es claramente reducido en relación con el número de mandatos. Sabemos que 134 delegados fueron responsables de 138 mandatos. Pues bien: según las noticias recopiladas, solo en 24 de aquellos 138 mandatos se registraron conflictos que llegaron a la prensa (un 17,39\%). Incluso considerando que los datos recogidos sean una muestra y que algunas noticias de conflicto se hayan quedado fuera de las búsquedas efectuadas, no parece que alcancen —ni en la mejor de las estimaciones al alza - una tercera parte del total. En otros términos: en la mayor parte de los mandatos no se produjeron conflictos públicos con las autoridades autonómicas. Y hay razones que pueden explicarlo. Por una parte, los delegados ostentan una clara dimensión representativa, que les conduce a desarrollar un papel mediador centro-periferia sin responsabilidades ejecutivas nítidas más allá de la coordinación del orden y la seguridad. Esa posición difícilmente les convierte en un actor para la confrontación, pues de ellos no dependen las posibles soluciones ni tienen capacidad efectiva de negociación. Pueden abrir cauces de diálogo, pero no tienen en sus 
manos recursos e instrumentos propios para alcanzar acuerdos sin la intervención y aquiescencia del Gobierno al que representan. Por ello, las tensiones tienden a verificarse ante ciertos ministerios, ante el Gobierno en su conjunto o ante el presidente, pero no tiene mucho sentido práctico el orientar las estrategias de confrontación contra la Delegación de Gobierno. La segunda razón deriva de la proximidad y relaciones entre el delegado y la autonomía de destino. Aunque el delegado es un representante, en absoluto es ajeno a las circunstancias locales y los intereses que puedan estar en juego. Incluso, ha habido y hay delegados que son candidatos por sus respectivos partidos en las elecciones autonómicas o generales (en este último caso representando a una provincia de la comunidad), y eso invita al delegado a intentar encauzar los problemas evitando su propio desgaste político ante la comunidad autónoma, por más que mantengan la fidelidad al Gobierno que les ha nombrado.

Tabla 3. Número de mandatos en delegaciones del Gobierno por filiación politica del delegado y de la comunidad autónoma (1996-2018)

Partido gobernante en comunidad autónoma

\begin{tabular}{lcccccccccc}
\hline $\begin{array}{l}\text { Militancia } \\
\text { política }\end{array}$ & PP & PSOE & $\begin{array}{l}\text { PP/PSOE } \\
\text { PSOE/PP }\end{array}$ & $\begin{array}{l}\text { PNV yotros } \\
\text { nacionalistas }\end{array}$ & nacionalistas & Coalición & Canaria & Otros & Total \\
\hline PP & 30 & $16(5)$ & 11 & $3(3)$ & 3 & $3(1)$ & 1 & $8(1)$ & 75 \\
\hline PSOE & $27(10)$ & 10 & 4 & 3 & 2 & $5(3)$ & $2(1)$ & 6 & 59 \\
\hline Otros & 0 & 0 & 1 & 0 & 0 & 1 & 0 & 2 & 4 \\
\hline Totales & 57 & 26 & 16 & 6 & 5 & 9 & 3 & 16 & 138 \\
\hline
\end{tabular}

Nota: entre paréntesis: número de conflictos detectados.

Fuente: nombramientos de delegados en el BOE. Elaboración propia.

En otras palabras: si una autonomía se enfrenta con el Gobierno central, el delegado poco puede resolver por sí mismo. Las reclamaciones deben solventarse mediante un acuerdo efectivo que se sitúa más allá de las posibilidades de la Delegación del Gobierno. Aún más esclarecedor es la distribución territorial de los conflictos delegado-autonomía recogida en la tabla número 4: 
Tabla 4. Distribución territorial de los conflictos delegado-autonomía

\begin{tabular}{lll}
\hline Comunidad autónoma & N. ${ }^{\circ}$ delegados & Conflictos \\
\hline Andalucía & 8 & 1 \\
\hline Aragón & 5 & 1 \\
\hline Asturias & 7 & 0 \\
\hline Canarias & 9 & 4 \\
\hline Cantabria & 5 & 0 \\
\hline Castilla y León & 6 & 2 \\
\hline Castilla-La Mancha & 9 & 2 \\
\hline Cataluńa & 7 & 0 \\
\hline Ceuta & 8 & 0 \\
\hline Comunidad Valenciana & 11 & 0 \\
\hline Extremadura & 6 & 0 \\
\hline Galicia & 9 & 0 \\
\hline Baleares & 7 & 2 \\
\hline La Rioja & 4 & 0 \\
\hline Madrid & 9 & 4 \\
\hline Melilla & 7 & 2 \\
\hline Murcia & 8 & 2 \\
\hline Navarra & 6 & 2 \\
\hline País Vasco & 7 & \\
\hline
\end{tabular}

Fuente: nombramientos de delegados en el BOE y prensa. Elaboración propia.

Como puede comprobarse, el grado de conflicto delegado-comunidad autónoma es en general bajo, varía territorialmente y puede resultar sorprendente porque las comunidades que más tensiones sostienen con el Gobierno central no acusan un alto nivel de tensiones con la Delegación del Gobierno. El dato resulta aún más llamativo si tenemos en cuenta que todas las regiones han sostenido conflictos con el Gobierno central a través de recursos ante el Tribunal Constitucional desde 1980, destacándose Cataluña con más de un $30 \%$ de los casos (seguida del País Vasco con más de un 16\% y, a distancia, 
Galicia y Andalucía con alrededor del $8 \%$ de todos los recursos) ${ }^{29}$. Veamos a continuación con mayor detalle lo ocurrido en algunas de estas comunidades.

Andalucía ha sido un ejemplo de baja conflictividad relativa. Pese a que hubo antes de 1996 algún conflicto con motivo de la posición de la UCD ante el proceso autonómico andaluz ${ }^{30}$, lo cierto es que las relaciones han sido en general de respeto institucional ${ }^{31}$. La excepción fueron las tensiones entre la delegada Carmen Crespo (PP) y la Junta a cuenta de diversas cuestiones relacionadas con la financiación autonómica ${ }^{32}$. Aragón ha sido también otra comunidad de baja conflictividad, aunque Gustavo Alcalde (PP) fue criticado por varios grupos parlamentarios por unas declaraciones sobre un caso de violencia de género ${ }^{33}$.

Canarias, sin embargo, acusa un reemplazo frecuente de delegados y una elevada conflictividad. El ańo 2008 fue especialmente delicado porque pasaron tres delegados por las islas. José Segura Clavell (PSOE) sostuvo una tensa relación con el Gobierno de Coalición Canaria y fue sustituido por Salvador García Llanos durante unos meses. En mayo llegó Carolina Darias. El caballo de batalla con la Delegación sería la reivindicación de una policía autonómica y la tendencia hacia el soberanismo. Más tarde, en 2016, el delegado Hernández Bento sostuvo un pulso contra la reclamación del uso de la bandera de Coalición Canaria en vez de la de la comunidad ${ }^{34}$.

Castilla-León mantuvo una sintonía general al ser el PP el partido que estaba al frente de la autonomía y de la delegación del Gobierno. No obstante, los roces crecieron relativamente durante el mandato del delegado Miguel Alejo Vicente (PSOE) que exigió el cese del enfrentamiento con el primer Gobierno de Rodríguez Zapatero ${ }^{35}$. En Castilla-La Mancha, donde el Gobierno regional estuvo casi siempre en manos del PSOE, se produjeron

29 Rodríguez; Harguindéguy y Sánchez (2018).

30 El País, 27-4-1982. El grupo parlamentario del PSOE pide el cese del delegado general Félix Manuel Pérez Miyares (UCD). Disponible en: https://bit.ly/2RTwBsV.

31 El Pais, 13-5-2000. Con Torres Hurtado, por ejemplo, siempre hubo una relación correcta y mantuvo el cargo durante los gobiernos Aznar. Disponible en: https://bit. ly/3mAw90z.

32 El País, 27-12-2012. Disponible en: https://bit.ly/3mtFhmG. También 26-9-2014. Disponible en: https://bit.ly/2FI4QRr.

33 Heraldo de Aragón, 24-2-2016. Disponible en: https://bit.ly/35KSPp0.

34 La Provincia, 6-1-2008. También 10-2-2008. ABC, 23-5-2008. Disponible en: https://bit.ly/2FLxv85. Sobre la bandera, véase: https://bit.ly/2RFNy9Z.

35 Diario de León, 23-3-2005. Véase: https://bit.ly/3mBmAlu. También El Norte de Castilla, 11-8-2008. Véase: https://bit.ly/3ku9u4f. 
presiones sobre el delegado para adecentar los cuarteles de la Guardia Civil ${ }^{36}$, pero no sería hasta 2015 cuando sí se produjeron roces intensos con el delegado José Julián Gregorio López (PP) al atacar con descalificativos al presidente de la comunidad (Emiliano García-Page) ${ }^{37}$. Este parece ser que fue un caso bastante excepcional porque la mayor parte de los delegados del Gobierno suelen atenerse a su papel de representantes y mediadores, además de ser coordinadores de los servicios de seguridad ciudadana. Es significativo, al respecto, que no hayamos encontrado conflictos del mismo tipo en comunidades como la de Cataluña donde, pese a la presencia de fuerzas independentistas, se ha verificado siempre un respeto institucional desde la Delegación del Gobierno ${ }^{38}$. Es bien conocido que el Gobierno catalán se ha venido enfrentando al Gobierno central para obtener cesiones del mismo, pero el terreno de la confrontación se ha verificado a través de recursos ante el Tribunal Constitucional ${ }^{39}$. Este resulta un cauce potencialmente más provechoso, pues el delegado carece de capacidad negociadora como respuesta ante el nivel de las reclamaciones de aquella comunidad.

Las ciudades autónomas de Ceuta y Melilla comparten unas peculiaridades singulares (proximidad a Marruecos, situación en el Estrecho, límites del territorio). Sin embargo, y según la prensa consultada, las tensiones son imperceptibles en Ceuta, pero no así en Melilla, donde el presidente Juan José Imbroda ha mantenido roces con el delegado Fernández Chacón (2004-2008) y con Sabrina Moh (2018). El primero acusó al Gobierno autónomo de querer enrarecer las relaciones entre Espańa y Marruecos por la instalación de la valla; la segunda lo denunció por haber «abandonado» a la ciudad en materia educativa durante dos legislaturas ${ }^{40}$. Es de señalar que Fernández Chacón fue posteriormente delegado en Ceuta y allí, según nuestros datos, no se

36 ABC, 21-9-2001. Disponible en: https://bit.ly/32JJE6g.

37 Diario de Castilla-La Mancha, 1-3-2017. Véase: https://bit.ly/33M8B02.

38 Véase, por ejemplo, una de las reuniones entre el delegado y el presidente de la Generalitat en el año 2010. Disponible en: https://bit.ly/2IZPUiL. Lejos quedaban los roces de 1982 y 1983 con los delegados Roviera o Martí. El País, 3-8-1982 y 13-31983. Disponible en: https://bit.ly/2El4Rdu y https://bit.ly/2EfYloh.

39 Al respecto, es indicativo que la comunidad con la que más recursos de inconstitucionalidad y conflictos de competencias se ha sostenido haya sido Cataluña. Véase: Rodríguez et al. (2018).

40 Europa Press, 28-32006 y Melilla Hoy, 28-9-2018. Disponible en: https://bit. ly/2HeS65g y https://bit.ly/32HuG0u. El que en Ceuta no hubiese roces con el delegado del Gobierno no la eximió de problemas, algunos de ellos graves como los sucesos del 11-10-1995. 
produjeron divergencias de la misma naturaleza. Por tanto, todo parece apuntar a que una buena parte de la causa de conflicto está relacionada con las circunstancias coyunturales y la actitud de los actores (delegado y responsables del Gobierno autonómico).

Como hemos indicado, en este trabajo no estamos contabilizando otros posibles roces protagonizados por otros elementos que no sean el Gobierno de la comunidad o, como máximo, el Parlamento autonómico. No entra en esta contabilización, por ejemplo, el caso de Extremadura, donde el delegado Óscar Baselga (PP) descalificó al PSOE como «compañero de viaje de terroristas» por acusaciones del grupo parlamentario socialista en el Congreso ${ }^{41}$. Allí no se produjeron - que tengamos noticia- conflictos públicos entre comunidad y delegado.

En Baleares sí se registraron conflictos, especialmente a partir del año 2015, cuando Francina Armengol (PSOE) se convirtió en la presidenta balear. El primero se produjo con la delegada Teresa Palmer Tous (2012-2016) cuando el Parlamento balear solicitó su comparecencia con motivo del suicidio de una mujer que había denunciado repetidamente el acoso de su expareja. Ciertamente, la delegada estaba obligada a comparecer, pero ante el Congreso de los Diputados; aquella maniobra de desgaste (apoyada incluso por el PP balear) se basaba en un creciente enfrentamiento que culminaría con la llegada de la siguiente delegada, María Salom (2016-2018). A ella se enfrentó abiertamente Armengol acusándola de obstaculizar el catalán y le pedía que se dedicase a las tareas consideradas exclusivas de la Delegación del Gobierno: la seguridad ${ }^{42}$.

Murcia representa un paradigma de enfrentamiento entre Gobierno regional y delegado cuando pertenecen a distintos partidos. En este caso tenemos una comunidad bajo control del PP que solo registra conflictos con los delegados cuando estos pertenecen al PSOE. No fue ninguna casualidad que no hubiera roces entre 2011 y 2018, mientras que sí se acusaron durante en el período 2004-2011 y desde julio de 2018. Los motivos de fricción son variados, pero recurrentes, y ocupan un lugar destacado la inmigración y la falta de agua. Ya en 2005 el presidente Ramón Luis Valcárcel acusó al delegado Ángel González (2004-2008) de no avisarle del traslado de inmigrantes subsaharianos a la región, llegándose al extremo de dejar «abandonados a su suerte» a un grupo en el aeropuerto de San Javier ${ }^{43}$. Más enconamiento se

41 El Pais, 24-5-1997. Disponible en: https://bit.ly/2FJnw35.

42 Diario de Ibiza, 15-10-2015. Disponible en: https://bit.ly/3iPVUI0. La Vanguardia, 15-5-2018. Disponible en: https://bit.ly/2FOB3pS.

43 La Opinión de Murcia, 27-1-2005. Disponible en: https://bit.ly/3hT4Xqx. 
registró durante el mandato del delegado Rafael González Tovar (2008-2011), aunque se produjo un matiz en las críticas: estas no procedían tanto del Gobierno regional como de la organizacional regional del PP. Obviamente, el Gobierno autonómico compartía esta estrategia en tanto en cuanto que miembros del PP de Murcia pertenecían también al Ejecutivo autonómico, pero con ello se ahorraban proyectar una imagen pública de enfrentamiento institucional, trasladando la tensión a la esfera exclusivamente partidista. Así, por ejemplo, en febrero de 2009 el PP regional pidió explicaciones al delegado por su "caótica» gestión de la inmigración. Al año siguiente fue el mismo partido el que solicitó su cese desde el Senado por la agresión sufrida por un senador popular en una concentración. Un tiempo más tarde, en 2012, cuando González Tovar ya había dejado de ser delegado, el PP murciano no dejó de recordarle. El portavoz del grupo parlamentario Popular, Juan Carlos Ruiz, le espetó al exdelegado (por entonces secretario general del PSOE de Murcia) que durante su mandato la comunidad «sufrió el mayor abandono por parte del Gobierno central y en la que se golpeó y dañó a Murcia» ${ }^{44}$. Con el siguiente delegado (Diego Conesa que, además, es secretario general de los socialistas murcianos y candidato a presidente de la comunidad autónoma) las tensiones se han reproducido desde junio de 2018 (primer Gobierno de Pedro Sánchez). A este delegado se le ha criticado desde la órbita partidista e, incluso, desde el grupo popular del Parlamento de Murcia por hacer campaña desde la Delegación del Gobierno, aunque no se han registrado choques institucionales con el Gobierno autonómico. Conesa, por su parte, se ha lanzado también a la arena del debate tachando a Ciudadanos y al PP de tener «el síndrome de Vox», pero desde su condición de secretario general, no como delegado del Gobierno (por más que se detecta una cierta confusión entre las dos facetas $)^{45}$.

En Navarra sí hemos detectado conflicto institucional, aparte de las habituales controversias partidistas. El delegado Vicente Ripa (2004-2008) tuvo que hacer frente a la falta de colaboración de la Policía Foral y la Local para combatir la droga en los colegios, advirtiendo que había que «[...] respirar mucho para adentro para seguir firme como defensor de la mesura entre instituciones, porque los partidos políticos tienen sus reglas del juego y los partidos jugarán con esas cartas, pero las instituciones tenemos que respetar las reglas

44 La Razón, 22-2-2009. La Opinión de Murcia, 23-12-2010. Disponible en: https://bit. ly/3hMfBzc. Europa Press, 12-4-2012. Disponible en: https://bit.ly/3kwJ41P.

45 Europa Press, 4-10-2018. Disponible en: https://bit.ly/3cfubht. 20 minutos, 16-102018. Disponible en: https://bit.ly/2ZRtrdi. Europa Press, 25-11-2018. Disponible en: https://bit.ly/3iGlmj4. La Verdad, 12-2-2019. Disponible en: https://bit. ly/33KNj2O. 
del juego» ${ }^{46}$. También desde los partidos, en particular desde Unión del Pueblo Navarro (UPN), se criticó al delegado, pero queda fuera de los propósitos de este estudio por no reflejar conflicto entre instituciones ${ }^{47}$. Años más tarde, la delegada Carmen Alba (2012-2018) sostuvo con la presidenta de la comunidad foral un debate sobre la conveniencia de la encarcelación de miembros del Gobierno catalán por declarar unilateralmente la independencia ${ }^{48}$. En ese contexto, el portavoz parlamentario de Bildu exigió el cese de la delegada y de la propia Delegación del Gobierno por no tener, a su juicio, «sentido» este tipo de instituciones ${ }^{49}$.

Similares circunstancias a las de Navarra se dieron en el País Vasco; también allí se verificó un enfrentamiento institucional entre la Delegación del Gobierno y el Gobierno autonómico. El delegado Enrique Villar (19962004) mantuvo siempre una relación tensa con los Gobiernos del Partido Nacionalista Vasco (PNV) ${ }^{50}$. Años más tarde, el delegado Carlos María Urquijo (2012-2016) sería cesado por el acercamiento del Gobierno de Mariano Rajoy al PNV en medio de la creciente crisis con Cataluña. Ese acercamiento propició la designación de Javier de Andrés Guerra como delegado del Gobierno que el presidente Urkullu mirará con buenos ojos para obtener más ventajas, aunque subrayando que el cargo debería ser suprimido en el País $\operatorname{Vasco}^{51}$. A partir de ahí tendrá lugar una relación tensa en la medida en que el proceso independentista catalán avance y termine aplicándose el art. 155 de la Constitución de $1978^{52}$.

Madrid es un caso relativamente especial por la identificación que se produce allí entre el delegado y el propio Gobierno central que lo designó. Las tensiones han venido siendo importantes cuando el PSOE ha formado Gobierno, algo normal si tenemos en cuenta que la Asamblea de Madrid ha

46 Europa Press, 13-1-2006. Disponible en: https://bit.ly/35NAB6g. Diario de Noticias, 16-1-2006. Disponible en: https://bit.ly/2ZSMP9P.

47 UPN. Disponible en: https://bit.ly/2FMHGsO. Europa Press, 12-12-2006. Disponible en: https://bit.ly/3mzaKoD.

48 Diario de Navarra, 2-11-2017. Disponible en: https://bit.ly/33B598o.

49 Diario de Navarra, 3-8-2017. Disponible en: https://bit.ly/2RECdH0.

50 El Pais, 16-10-2003. Disponible en: https://bit.ly/3iOs5aL. El Mundo, 23-3-2010. Disponible en: https://bit.ly/3mADw8f.

51 Libertad Digital, 30-12-2016. Disponible en: https://bit.ly/32HAbwd. $A B C$, 4-1-2017. Disponible en: https://bit.ly/2ZTiB6y. El Español, 19-1-2017. Disponible en: https://bit.ly/3mCTqiD.

52 Son numerosas las noticias de esa tensión: https://bit.ly/2RIrITm; https://bit.ly/2HjcZfL; https://bit.ly/32Mbpv8; https://bit.ly/3iLQFJo. 
estado en manos del PP desde el año 1995. En consecuencia, las tensiones se verificaron tanto con el delegado Constantino Méndez (2004-2006, año este último en el que tuvo que dimitir tras ser reprobado por la Asamblea de Madrid), como con Soledad Mestre (2006-2009) y Amparo Valcarce (2009$2011)^{53}$. Tras una serie de ańos de Gobierno popular sin enfrentamientos, ha vuelto la tensión con la llegada del delegado José Manuel Rodríguez Uribes (desde junio de 2018) y las huelgas de taxis ${ }^{54}$.

Así pues, han sido veinticuatro los conflictos detectados, quince de los cuales se han producido entre el PP y el PSOE. Los restantes han tenido lugar con Gobiernos autonómicos en manos de otros partidos (País Vasco, Canarias, Navarra, etc.) por parte de delegados tanto pertenecientes al PSOE como al PP. No hemos detectado casos de conflicto cuando el delegado pertenece al mismo partido que la fuerza política que sustenta al Gobierno autonómico ${ }^{55}$.

\section{CONCLUSIONES}

Tras lo expuesto, las principales conclusiones del trabajo son las siguientes:

- El nombramiento de delegados se encuentra estrechamente relacionado con los cambios del Gobierno central, particularmente cuando dichos cambios conllevan también cambio de partido. Tras las elecciones de 1996, 2004 y 2011 cambiaron todos los delegados, al igual que ha ocurrido en junio de 2018 tras la moción de censura que produjo el ascenso del Gobierno socialista de Pedro Sánchez. No hay relación significativa con los cambios de gobierno autonómico.

53 Méndez Martínez, Constantino (2004-2006): $A B C$, 9-5-2006. Disponible en: https://bit.ly/3chPqz5. El País, 30-6-2007. Disponible en: https://bit.ly/3kr66Ha. Mestre García, Soledad (2006-2009): «Su mandato estuvo plagado de críticas del gobierno regional, del PP, y de algunos sindicatos policiales»: El País, 6 -4-2012. Disponible en: https://bit.ly/2EeLKS8. Valcarce García, Amparo (2009-2011): «El PP fuerza a la Asamblea a votar el cese de Valcarce»: El País, 4-3-2011. Disponible en: https://bit.ly/3mzSj35. «Arrecia la bronca entre la delegada y Granados por el caos de la A-6»: El Pais, 8-3-2011. Disponible en: https://bit.ly/2RH6pBG.

5420 minutos, 28-1-2019. Disponible en: https://bit.ly/2FzTj6Q.

55 El que no saltasen a la prensa conflictos en los casos de coincidencia de partido no significa que no existieran. Valga un ejemplo (aunque anterior a 1997): Eugenio Faraco Munuera fue delegado del PSOE en Murcia (1994-1996), pero se llevó personalmente mejor con el presidente Valcárcel que con el PSOE. La Verdad de Murcia, 28-11-2009. Disponible en: https://bit.ly/2RCQ40K. 
- La mayoría de los delegados son oriundos de la comunidad autónoma a la que son destinados porque se busca en el delegado un mediador entre el Gobierno central y el autonómico. Además, un número importante de delegados ocupan puestos relevantes dentro de la organización regional de sus partidos, e incluso llegan a ser candidatos en las elecciones generales o en las autonómicas.

- El perfil socioprofesional no varía significativamente entre los dos partidos (PP o PSOE) a los que pertenecen el $97 \%$ de los delegados. Las características compartidas son: formación universitaria (sobre todo en Derecho), pertenencia a cuerpos de funcionarios, amplia experiencia política previa y edad superior a los cuarenta años en la toma de posesión del cargo.

- El cargo de delegado normalmente es un eslabón más en una cadena de posiciones de responsabilidad política, pero en la mayor parte de los casos se registra una intensa experiencia política previa, superior a la experiencia política posterior. Ello se encuentra en concordancia con la edad relativamente elevada de los delegados y con la retirada de la vida pública de muchos de ellos tras desempeñar el cargo.

- El nivel de conflicto delegados/Gobiernos autonómicos (tal y como lo hemos definido aquí) es relativamente bajo. No llegan ni a un $25 \%$ los mandatos que han registrado conflictos que hayan sido recogidos por los medios. Otra cuestión es que un partido critique al delegado (o que el partido del delegado haga lo contrario), pero fuera de la esfera institucional que estamos tratando. No se han verificado tensiones o conflictos entre delegados y Gobiernos autonómicos cuando pertenecen al mismo partido. Los conflictos detectados se han dado mayoritariamente entre un delegado del PP y una comunidad en manos del PSOE o a la inversa.

- Las principales líneas de tensión entre Gobierno central y comunidades no se verifica a través de las delegaciones de Gobierno. Es mucho más perceptible a través de los recursos de inconstitucionalidad presentados ante el Tribunal Constitucional y la negociación directa de cesión de competencias. Cataluña, por ejemplo, es la comunidad que más recursos de inconstitucionalidad ha presentado y sin embargo no ha sostenido relaciones de abierto conflicto con la Delegación de Gobierno.

- Recientemente se percibe una mayor relación de los delegados con la política autonómica en el sentido de que llegan a abandonar el cargo para presentarse como candidatos a elecciones autonómicas o generales. Ese rasgo hace más compleja la función mediadora y de coordinación entre Gobiernos por parte de los delegados. 


\section{ANEXO}

\section{Delegados del Gobierno por mandatos (I996-20i 8)}

\begin{tabular}{|c|c|c|c|c|}
\hline Apellidos & Nombre & Com. autónoma & Nombramiento & Cese \\
\hline Ansuátegui Gárate & Francisco Javier & Navarra & $18-5-1996$ & $13-5-2000$ \\
\hline Baselga Laucirica-Neira & Óscar & Extremadura & $18-5-1996$ & $24-4-2004$ \\
\hline Cirer Adrover & Catalina & Islas Baleares & $18-5-1996$ & $1-2-2003$ \\
\hline Cuartas Galván & Alberto Javier & Cantabria & $18-5-1996$ & $20-9-2003$ \\
\hline Diz Guedes & Juan Miguel & Galicia & $18-5-1996$ & $13-5-2000$ \\
\hline Fernández Noval & Fernando Ramón & Asturias & $18-5-1996$ & $20-5-2000$ \\
\hline García Monge & Isaías & Castilla y León & $18-5-1996$ & $24-4-2004$ \\
\hline García-Valdecasas Salgado & Julia & Cataluña & $18-5-1996$ & $6-9-2003$ \\
\hline González Cepeda & Carlos & $\begin{array}{l}\text { Comunidad } \\
\text { Valenciana }\end{array}$ & $18-5-1996$ & $13-5-2000$ \\
\hline López Ojeda & Antonio & Canarias & $18-5-1996$ & $24-4-2004$ \\
\hline López San Miguel & Tomás & La Rioja & $18-5-1996$ & $1-5-2004$ \\
\hline Moro Moreno & Carlos & $\begin{array}{l}\text { Castilla-La } \\
\text { Mancha }\end{array}$ & $18-5-1996$ & $13-5-2000$ \\
\hline Núñez Morgades & Pedro & Madrid & $18-5-1996$ & $13-5-2000$ \\
\hline Peñarrubia Agius & Joaquín & Murcia & $18-5-1996$ & $31-1-2004$ \\
\hline Rosel Onde & Luis Antonio & Aragón & $18-5-1996$ & $13-5-2000$ \\
\hline Torres Hurtado & José & Andalucía & $18-5-1996$ & $7-9-2002$ \\
\hline Villar Montero & Enrique & País Vasco & $18-5-1996$ & $10-1-2004$ \\
\hline Beamud Martín & Enrique & Melilla & $25-5-1996$ & $13-5-2000$ \\
\hline Cosió Romero & Javier & Ceuta & $25-5-1996$ & $18-7-1998$ \\
\hline Moro Díaz & Luis Vicente & Ceuta & $18-7-1998$ & $1-5-2004$ \\
\hline Ameijide Montenegro & Eduardo & Aragón & $13-5-2000$ & $24-4-2004$ \\
\hline Ansuátegui Gárate & Francisco Javier & Madrid & $13-5-2000$ & 24-4-2004 \\
\hline Esteban Albert & Arturo & Melilla & $13-5-2000$ & $1-5-2004$ \\
\hline $\begin{array}{l}\text { Fernández de Mesa Díaz del } \\
\text { Río }\end{array}$ & Arsenio & Galicia & $13-5-2000$ & $31-1-2004$ \\
\hline Iribas Mielgo & José Carlos & Navarra & $13-5-2000$ & $1-5-2004$ \\
\hline Mas Rubio & Carmen & $\begin{array}{l}\text { Comunidad } \\
\text { Valenciana }\end{array}$ & $13-5-2000$ & $6-4-2002$ \\
\hline Zoido Álvarez & Juan Ignacio & $\begin{array}{l}\text { Castilla-La } \\
\text { Mancha }\end{array}$ & $13-5-2000$ & $7-9-2002$ \\
\hline Fernández González & Mercedes & Asturias & $20-5-2000$ & $1-5-2004$ \\
\hline Camps Ortiz & Francisco & $\begin{array}{l}\text { Comunidad } \\
\text { Valenciana }\end{array}$ & $6-4-2002$ & $7-9-2002$ \\
\hline Cotino Ferrer & Juan Gabriel & $\begin{array}{l}\text { Comunidad } \\
\text { Valenciana }\end{array}$ & $7-9-2002$ & $24-4-2004$ \\
\hline
\end{tabular}




\begin{tabular}{|c|c|c|c|c|}
\hline Apellidos & Nombre & Com. autónoma & Nombramiento & Cese \\
\hline Naharro de Mora & María Encarnación & $\begin{array}{c}\text { Castilla-La } \\
\text { Mancha }\end{array}$ & $7-9-2002$ & $31-1-2004$ \\
\hline Zoido Álvarez & Juan Ignacio & Andalucía & $7-9-2002$ & $24-4-2004$ \\
\hline Ramis Socías & Miguel Ángel & Islas Baleares & $1-2-2003$ & $1-5-2004$ \\
\hline Bouis Gutiérrez & Susana & Cataluña & $6-9-2003$ & $1-5-2004$ \\
\hline Nalda Condado & Pedro & Cantabria & $20-9-2003$ & $24-4-2004$ \\
\hline Urquijo Valdivielso & Carlos María & País Vasco & $10-1-2004$ & $24-4-2004$ \\
\hline Lobo Asenjo & Jaime & $\begin{array}{c}\text { Castilla-La } \\
\text { Mancha }\end{array}$ & $31-1-2004$ & $24-4-2004$ \\
\hline Marqués Fernández & Francisco & Murcia & $31-1-2004$ & $1-5-2004$ \\
\hline Alejo Vicente & Miguel & Castilla y León & $24-4-2004$ & 14-1-2012 \\
\hline Ameijeiras Vales & Manuel & Galicia & $24-4-2004$ & $25-4-2009$ \\
\hline Bernabé García & Antonio & $\begin{array}{c}\text { Comunidad } \\
\text { Valenciana }\end{array}$ & $24-4-2004$ & $17-5-2008$ \\
\hline Fernández López & Javier & Aragón & $24-4-2004$ & 6-1-2012 \\
\hline Ibáñez Ramos & Agustín Jesús & Cantabria & $24-4-2004$ & $31-12-2011$ \\
\hline Luesma Correas & Paulino & País Vasco & $24-4-2004$ & $1-5-2008$ \\
\hline Méndez Martínez & Constantino & Madrid & $24-4-2004$ & $13-5-2006$ \\
\hline Pereira Santana & Carmen & Extremadura & $24-4-2004$ & 6-1-2012 \\
\hline Segura Clavell & José & Canarias & $24-4-2004$ & $2-2-2008$ \\
\hline Valmorisco Martín & María del Carmen & $\begin{array}{c}\text { Castilla-La } \\
\text { Mancha }\end{array}$ & $24-4-2004$ & $21-9-2005$ \\
\hline Viera Chacón & José Antonio & Andalucía & $24-4-2004$ & 28-8-2004 \\
\hline Fernández Chacón & José & Melilla & $1-5-2004$ & $1-5-2008$ \\
\hline González Hernández & Ángel & Murcia & $1-5-2004$ & $17-5-2008$ \\
\hline Nieto González & Jerónimo & Ceuta & $1-5-2004$ & $20-5-2006$ \\
\hline Rangel i Tarrés & Joan & Cataluña & $1-5-2004$ & $8-10-2011$ \\
\hline Ripa González & Vicente & Navarra & $1-5-2004$ & $1-5-2008$ \\
\hline Socías Puig & Ramón Antonio & Islas Baleares & $1-5-2004$ & $31-12-2011$ \\
\hline Trevín Lombán & Antonio Ramón & Asturias & $1-5-2004$ & 15-10-2011 \\
\hline Ulecia Rodríguez & José Antonio & La Rioja & $1-5-2004$ & $31-12-2011$ \\
\hline López Garzón & Juan José & Andalucía & $28-8-2004$ & $18-10-2010$ \\
\hline Díaz-Cano del Rey & Máximo Ramón & $\begin{array}{l}\text { Castilla-La } \\
\text { Mancha }\end{array}$ & $21-9-2005$ & $14-1-2012$ \\
\hline Mestre García & María Soledad & Madrid & $17-5-2006$ & $28-4-2009$ \\
\hline García-Arreciado Batanero & José Jenaro & Ceuta & $20-5-2006$ & $1-5-2008$ \\
\hline García Llanos & Salvador & Canarias & $2-2-2008$ & $17-5-2008$ \\
\hline Cabieces García & Miguel Ángel & País Vasco & $1-5-2008$ & 6-1-2012 \\
\hline Escobar Marcos & Gregorio Francisco & Melilla & $1-5-2008$ & $2-4-2011$ \\
\hline Fernández Chacón & José & Ceuta & $1-5-2008$ & $31-12-2011$ \\
\hline Sáiz Delgado & Elma & Navarra & $1-5-2008$ & 6-1-2012 \\
\hline
\end{tabular}




\begin{tabular}{|c|c|c|c|c|}
\hline Apellidos & Nombre & Com. autónoma & Nombramiento & Cese \\
\hline Darías Sansebastián & Carolina & Canarias & $17-5-2008$ & $2-4-2011$ \\
\hline González Tovar & Rafael & Murcia & $17-5-2008$ & $31-12-2011$ \\
\hline Peralta Ortega & Ricardo Fernando & $\begin{array}{c}\text { Comunidad } \\
\text { Valenciana }\end{array}$ & $17-5-2008$ & $24-12-2010$ \\
\hline Louro Goyanes & Antón & Galicia & 28-4-2009 & $2-4-2011$ \\
\hline Valcarce García & Amparo & Madrid & $28-4-2009$ & $2-4-2011$ \\
\hline García Garrido & Luis & Andalucía & $18-10-2010$ & $19-12-2011$ \\
\hline Botella Gómez & Ana & $\begin{array}{c}\text { Comunidad } \\
\text { Valenciana }\end{array}$ & $24-12-2010$ & $31-12-2011$ \\
\hline Carrión Martín & María Dolores & Madrid & $2-4-2011$ & $14-1-2012$ \\
\hline Claret García & Antonio María & Melilla & $2-4-2011$ & 31-12-2011 \\
\hline Cortizo Nieto & Miguel Ángel & Galicia & 2-4-2011 & 15-10-2011 \\
\hline Fernández Fernández & Dominica & Canarias & $2-4-2011$ & $31-12-2011$ \\
\hline García Llovera & Montserrat & Cataluña & 8-10-2011 & $31-12-2011$ \\
\hline González Zapico & Francisco Martín & Asturias & $15-10-2011$ & 6-1-2012 \\
\hline Pose Mesura & José Manuel & Galicia & 15-10-2011 & 6-1-2012 \\
\hline Crespo Díaz & Carmen & Andalucía & $24-12-2011$ & $16-2-2015$ \\
\hline Bascuñana García & Joaquín & Murcia & $31-12-2011$ & $13-6-2015$ \\
\hline Bretón Rodríguez & Alberto & La Rioja & $31-12-2011$ & 19-6-2018 \\
\hline El Barkani Abdelkader & Abdelmalik & Melilla & $31-12-2011$ & 19-6-2018 \\
\hline González Pérez & Francisco Antonio & Ceuta & $31-12-2011$ & 20-6-2015 \\
\hline Hernández Bento & María del Carmen & Canarias & $31-12-2011$ & 14-11-2015 \\
\hline Llanos Luna Tobarra & María de los & Cataluña & $31-12-2011$ & 19-11-2016 \\
\hline Rodríguez Barberá & José María & Islas Baleares & $31-12-2011$ & 21-7-2012 \\
\hline Ruiz Fuertes & Samuel & Cantabria & $31-12-2011$ & 19-6-2018 \\
\hline Sánchez de León Guardiola & Paula & $\begin{array}{c}\text { Comunidad } \\
\text { Valenciana }\end{array}$ & $31-12-2011$ & $14-6-2014$ \\
\hline Alba Orduna & Carmen & Navarra & 6-1-2012 & $19-6-2018$ \\
\hline Alcalde Sánchez & Gustavo & Aragón & $6-1-2012$ & 19-6-2018 \\
\hline De Lorenzo Ferrera & Gabino & Asturias & $6-1-2012$ & 24-3-2018 \\
\hline Juárez Casado & Samuel Jesús & Galicia & 6-1-2012 & 15-11-2014 \\
\hline Ramírez del Molino Morán & Alejandro & Extremadura & $6-1-2012$ & $12-5-2012$ \\
\hline Urquijo Valdivielso & Carlos María & País Vasco & $6-1-2012$ & $31-12-2016$ \\
\hline Cifuentes Cuenca & Cristina & Madrid & $14-1-2012$ & $11-4-2015$ \\
\hline Labrador Encinas & Jesús & $\begin{array}{c}\text { Castilla-La } \\
\text { Mancha }\end{array}$ & $14-1-2012$ & $11-4-2015$ \\
\hline Ruiz Medrano & Ramiro Felipe & Castilla y León & $14-1-2012$ & $11-4-2015$ \\
\hline López Iglesias & Germán & Extremadura & $12-5-2012$ & $18-4-2015$ \\
\hline Palmer Tous & Teresa & Islas Baleares & 21-7-2012 & $21-5-2016$ \\
\hline Castellano Gómez & Serafín & $\begin{array}{c}\text { Comunidad } \\
\text { Valenciana }\end{array}$ & $14-6-2014$ & $30-5-2015$ \\
\hline
\end{tabular}




\begin{tabular}{|c|c|c|c|c|}
\hline Apellidos & Nombre & Com. autónoma & Nombramiento & Cese \\
\hline Villanueva Álvarez & Santiago & Galicia & $15-11-2014$ & $19-6-2018$ \\
\hline Sanz Cabello & Antonio & Andalucía & $21-2-2015$ & 19-6-2018 \\
\hline Dancausa Trevińo & $\begin{array}{l}\text { María de la } \\
\text { Concepción }\end{array}$ & Madrid & $11-4-2015$ & $19-6-2018$ \\
\hline Gregorio López & José Julián & $\begin{array}{l}\text { Castilla-La } \\
\text { Mancha }\end{array}$ & $11-4-2015$ & 19-6-2018 \\
\hline $\begin{array}{l}\text { Suárez-Quiñones y } \\
\text { Fernánez }\end{array}$ & Juan Carlos & Castilla y León & $11-4-2015$ & $11-7-2015$ \\
\hline Herrera Santa-Cecilia & Cristina & Extremadura & $25-4-2015$ & 19-6-2018 \\
\hline Fernández Cucurull & Nicolás & Ceuta & $20-6-2015$ & 19-6-2018 \\
\hline Moragues Ferrer & Juan Carlos & $\begin{array}{l}\text { Comunidad } \\
\text { Valenciana }\end{array}$ & $4-7-2015$ & $19-6-2018$ \\
\hline Salgueiro Cortińas & María José & Castilla y León & $25-7-2015$ & 19-6-2018 \\
\hline Sánchez Solís de Querol & Antonio & Murcia & $25-7-2015$ & 11-11-2017 \\
\hline Hernández Bento & Enrique & Canarias & $14-11-2015$ & $17-12-2016$ \\
\hline Millo i Rocher & Josep Enric & Cataluña & 19-11-2016 & 19-6-2018 \\
\hline Salom Coll & María & Islas Baleares & $19-11-2016$ & $19-6-2018$ \\
\hline Roldós Caballero & María Mercedes & Canarias & $17-12-2016$ & 19-6-2018 \\
\hline De Andrés Guerra & Javier & País Vasco & $31-12-2016$ & 19-6-2018 \\
\hline Bernabé Pérez & Francisco Martín & Murcia & $11-11-2017$ & 19-6-2018 \\
\hline Marín Albi & Mariano & Asturias & 24-3-2018 & 19-6-2018 \\
\hline Arasti Pérez & José Luis & Navarra & 19-6-2018 & \\
\hline Barcones Sanz & Virginia & Castilla y León & 19-6-2018 & \\
\hline Conesa Alcaraz & Diego & Murcia & 19-6-2018 & \\
\hline Cunillera i Mestres & Teresa & Cataluña & $19-6-2018$ & \\
\hline Fulgencio Tejedor & Juan Carlos & $\begin{array}{c}\text { Comunidad } \\
\text { Valenciana }\end{array}$ & $19-6-2018$ & \\
\hline García Seco & María Yolanda & Extremadura & $19-6-2018$ & \\
\hline González Ramos & Manuel Gabriel & $\begin{array}{l}\text { Castilla-La } \\
\text { Mancha }\end{array}$ & 19-6-2018 & \\
\hline Losa Carballido & Delia & Asturias & 19-6-2018 & \\
\hline Losada de Azpiazu & Javier & Galicia & 19-6-2018 & \\
\hline Loza Aguirre & Jesús & País Vasco & $19-6-2018$ & \\
\hline Máńez Rodríguez & Elena & Canarias & 19-6-2018 & \\
\hline Mateos Estudillo & $\begin{array}{l}\text { Salvadora del } \\
\text { Carmen }\end{array}$ & Ceuta & $19-6-2018$ & \\
\hline Moh Abdelkader & Sabrina & Melilla & 19-6-2018 & \\
\hline Pérez Sáenz & Ignacio & La Rioja & 19-6-2018 & \\
\hline Rodríguez Gómez de Celis & Alfonso & Andalucía & $19-6-2018$ & \\
\hline Rodríguez Uribes & José Manuel & Madrid & 19-6-2018 & \\
\hline Sánchez Grau & Rosario & Islas Baleares & $19-6-2018$ & \\
\hline
\end{tabular}




\begin{tabular}{llccc}
\hline Apellidos & Nombre & Com. autónoma & Nombramiento & Cese \\
\hline Sánchez Pérez & Carmen & Aragón & $19-6-2018$ & \\
\hline Zuloaga Martínez & Pablo & Cantabria & $19-6-2018$ & \\
\hline
\end{tabular}

\section{Bibliografía}

Agranoff, R. y Ramos Gallarín, J. A. (1997). Toward Federal Democracy in Spain: An Examination of Intergovernmental Relations. Publius, 27 (4), 1-38. Disponible en: https://doi.org/10.1093/oxfordjournals.pubjof.a029931.

Aja, E. y Colino, C. C. (2014). Multilevel Structures, Coordination and Partisan Politics in Spanish Intergovernmental Relations. Comparative European Politics, 12 (4-5), 444-467. Disponible en: https://doi.org/10.1057/cep.2014.9.

Aja, E. (2014). Estado autonómico y reforma federal. Madrid: Alianza.

Alba, C. R. (2000). Le gouverneur civil en Espagne: «un préfet pas comme les autres». Origine, développement et disparition. Revue Française d'Administration Publique, 96, 609-621.

Albertí Rovira, E. (1985). Las relaciones de colaboración entre el Estado y las comunidades autónomas. Revista Española de Derecho Constitucional, 14, 155-176.

Alonso de Antonio, A. L. (1997). Notas sobre los nuevos delegados del Gobierno. Revista de la Facultad de Derecho de la Universidad Complutense, 21 (ejemplar dedicado a: Las perspectivas del Derecho Autonómico (I)), 223-250.

Bassols Coma, M. (1988). El delegado del Gobierno como instrumento de coordinación y cooperación con las comunidades autónomas. En Ó. Alzaga (dir). Comentarios a las leyes politicas con Alzaga, Tomo II (pp. 469-477). Madrid: Cortes Generales; Editoriales de Derecho Reunidas.

Bueno Sánchez, J. M. (2015). La Administración periférica del Estado. Delegados del Gobierno en las comunidades autónomas y ciudades de Ceuta y Melilla. Subdelegados del Gobierno en las provincias. Comisiones provinciales. Servicios integrados y no integrados. En J. M. Bueno Sánchez, et al. (coord.). Lecciones fundamentales de derecho administrativo (parte general y parte especial) (pp. 757-770). Pamplona: Aranzadi Thompson Reuters.

Calvo González, M. A. (1979-1980). El delegado del Gobierno en las comunidades autónomas. Revista de Derecho Politico, 5, 121-127. Disponible en: https://doi.org/10.5944/ rdp.5.1979.8005.

Cámara del Portillo, D. (1981). La figura del delegado del Gobierno en las comunidades autónomas. Revista de Estudios de la Vida Local, 210, 247-264.

Coller, X. (coord.). (2016). El poder político en España: parlamentarios y ciudadania. Madrid: Centro de Investigaciones Sociológicas.

Díaz de Liaño y Argüelles, F. y Vallés Copeiro del Villar, A. (1980). Notas para un Estatuto del delegado del Gobierno en las comunidades autónomas. Documentación Administrativa, 187, 255-286.

Expósito Gómez, E. (2005). El delegado del Gobierno en las comunidades autónomas. En M. A. García Herrera (coord.). Constitución y democracia: 25 años de Constitución 
democrática en España: (actas del congreso celebrado en Bilbao los días 19 a 21 de noviembre de 2003). Vol. 2 (pp. 543-556). Bilbao: Universidad del País Vasco.

García Morales, M. J., Montilla Martos, J. A. y Arbós Marín, X. (eds.). (2006). Las relaciones intergubernamentales en el Estado autonómico. Madrid: Centro de Estudios Políticos y Constitucionales.

González Aperribay, J. (2011). ¿Para qué sirven los delegados del Gobierno? Atlántica XXII: Revista Asturiana de Información y Pensamiento, 17, 11-13.

González Escudero, M. T. (2004). La organización militar y las Delegaciones de Defensa. Delegados del Gobierno en Ceuta y Melilla. Asamblea: Revista Parlamentaria de la Asamblea de Madrid, 2 (Ejemplar dedicado a: Gobierno y Administración del Estado. Comentarios a la Ley 6/1997, de 14 de abril, de Organización y Funcionamiento de la Administración General del Estado), 533-540.

González Hernando, A. (1990). El delegado del Gobierno en las comunidades autónomas. Madrid: Ministerio del Interior.

Instituto Nacional de Administración Pública (1990). Informe sobre los convenios de colaboración entre la administración del Estado y las comunidades autónomas. Sometidos a la autorización de la comisión delegada del gobierno para la política autonómica durante 1988. Madrid: Instituto Nacional de Administración Pública.

Jerez Mir, M. J., Rodríguez Teruel, J. y Real Dato, J. (2012). ¿Quién gobierna en España? Las élites parlamentarias y ministeriales. En J. M. Reniu y J. A. Mellón. Sistema político español (pp. 189-203). Barcelona: Huygens.

Linde Paniagua, E. (1979). El delegado del Gobierno. Documentación Administrativa, 182, 255-286.

López Nieto, L. (ed.). (2006). Relaciones intergubernamentales en la España democrática. Interdependencia, autonomía, conflicto y cooperación. Madrid: Dykinson.

Martín Conty, I. y Martín Conty, J. L. (2017). El gobernador civil en España. Madrid: Ediciones Jurídicas Castillo de Luna.

Ministerio del Interior (1997). El Gobernador civil en la politica y en la Administración de la España contemporánea. Madrid: Ministerio del Interior.

Morena y de la Morena, L. de la (1985). Las competencias de los delegados del Gobierno y de los gobernadores civiles en materia de personal: articulación y régimen. Documentación Administrativa, 204, 179-201.

Oliván del Cacho, J. (1998). Los límites de la integración de los servicios territoriales ministeriales en las Delegaciones del Gobierno: examen de uno de los objetivos de la Ley de Organización y Funcionamiento de la Administración General del Estado. En Constitución y el nuevo diseño de las administraciones estatal y autonómica: XIX Jornadas de Estudio (pp. 337-352). Madrid: SOPEC.

Quiroga de Abarca, J. M. (1994). Centralización y descentralización administrativas y delegado del Gobierno. Madrid: Dykinson.

Ramió, C. (2016). La renovación de la función pública. Estrategias para frenar la corrupción política en España. Madrid: Los Libros de la Catarata.

Rodríguez López, E., Harguindéguy, J. B. y Sánchez Sánchez, A. (2018). The perfect storm? How to explain the rise of intergovernmental conflicts in Spain? (1984-2014). 
Innovation: The European Journal of Social Science Research, 32 (2), 211-230. Disponible en: https://doi.org/10.1080/13511610.2018.1520628.

Rubiales Torrejón, A. (2008). Una mujer de mujeres. Madrid: Aguilar.

Salaberri Barañano, R. (1989). El delegado del Gobierno. Oñati: Henri-Arduralaritzaren Euskal; Erakundea, Instituto Vasco de Administración Pública.

Sarmiento Larrauri, J. I. (2016). Los delegados del Gobierno. En J. M. Baño León (coord.). Memorial para la reforma del Estado: estudios en homenaje al Profesor Santiago Muñoz Machado, Vol. 2 (pp. 1845-1855). Madrid: Centro de Estudios Políticos y Constitucionales.

Ureta Domingo, J. C. (1983). El delegado del gobierno en las comunidades autónomas. Revista Vasca de Administración Pública, Herri-Arduralaritzako Euskal Aldizkaria, 5, 91-130.

Zafra Jiménez, A. (1998). Adaptación de la Administración periférica a las exigencias del Estado autonómico: los delegados del gobierno en las comunidades autónomas. Constitución y el nuevo diseño de las Administraciones estatal y autonómica: XIX Jornadas de Estudio (pp. 367-392). Madrid: SOPEC. 